\title{
7,8-Dihydroxyflavone Inhibits VEGF-Induced in Vitro Angiogenesis of RF/6A Cells via the Blocking of VEGFR2 Signaling Pathway
}

\section{Xiangwu Chen}

Fudan University Eye Ear Nose and Throat Hospital https://orcid.org/0000-0002-3013-6924

\section{Wang Yao}

Fudan University Eye Ear Nose and Throat Hospital Department of Ophthalmology

\section{Shuqi You}

Fudan University Eye Ear Nose and Throat Hospital

\section{Suqian Wu}

Fudan University Eye Ear Nose and Throat Hospital

\section{Gang Li}

Fudan University Eye Ear Nose and Throat Hospital

Xiaofen Mo ( $\nabla$ xfmo@fudan.edu.cn )

https://orcid.org/0000-0002-2933-0025

\section{Research article}

Keywords: 7,8-dihydroxyflavone, monkey, retinal, vascular, endothelial cells, neovascularization, neuroprotective

Posted Date: August 7th, 2020

DOl: https://doi.org/10.21203/rs.3.rs-45610/v1

License: (9) This work is licensed under a Creative Commons Attribution 4.0 International License. Read Full License 


\section{Abstract}

Background: This study aimed to investigate the anti-angiogenesis effect of 7,8-dihydroxyflavone (7,8DHF) and its potential molecular mechanism.

Methods: The rhesus macaque choroid-retinal endothelial (RF/6A) cells were treated with different concentrations (from 0 to $100 \mu \mathrm{M}$ ) of 7,8-DHF and/or $40 \mathrm{ng} / \mathrm{ml}$ VEGF. The morphology, proliferation, migration, capillary-like tube formation囚and apoptosis of RF/6A cells were evaluated by Giemsa staining, CCK-8 assay, transwell migration assay, matrigel tube formation assay, and flow cytometry/hoechst33342 staining, respectively. The protein content of VEFGR2 and p-VEGFR2 was assessed by western blotting.

Results: 7,8-DHF significantly inhibited the proliferation, migration, and tube formation of RF/6A cells and promoted their apoptosis in vitro. The expression of VEGFR2 in RF/6A cells was constant whether or not to administer 7,8-DHF. However, the phosphorylation of VEGFR2 significantly decreased after the administration of 7,8-DHF.

Conclusions: 7,8-DHF could inhibit RF/6A angiogenesis in vitro. The inhibitory mechanism of 7,8-DHF in angiogenesis was attributed to the suppression of VEGFR2 phosphorylation and thus blocking of VEGF/VEGFR2 signal pathway.

\section{Background}

Angiogenesis, the formation of new blood vessels from the pre-existing vasculature, is the primary cause of irreversible vision loss in a variety of retinal diseases, such as proliferative diabetic retinopathy (PDR), retinopathy of prematurity, and neovascular age-related macular degeneration (AMD)[1-3]. In clinical practice, these retinal vascular diseases are treated with anti-VEGF-A therapy since VEGF-A is a major stimulant of pathologic neovascularization[4]. However, VEGF is expressed in both normal and pathological retinal ganglion and photoreceptor cells, suggesting that this growth factor has a physiological function in ophthalmic neovascularization[5]. Thus, constant or excess anti-VEGF treatment in patients with angiogenesis-related diseases may result in gradual neurodegeneration[6]. Furthermore, ophthalmic vascular disorders, such as neovascular glaucoma, AMD, and DR, are always accompanied by ocular neuropathy, implying that anti-VEGF treatment alone is likely not sufficient. Therefore, it is important to develop an innovative agent that can block the VEGF-A signaling pathway while protecting the retinal neurons in patients with co-existing ophthalmic neuropathy and angiogenesis.

Flavonoids are naturally-occurring chemical substances that are commonly present in vegetables and fruits and exert various biological effects[7]. 7, 8-DHF, a newly discovered flavonoid derivative, has been shown to act as a high-affinity tropomyosin-associated kinase receptor B (TrkB) agonist that activates the downstream signaling pathway and exerts neuroprotective effects in neurological diseases[8]. As several flavonoids have been reported to have inhibitory effects on angiogenesis in various animal models $[9,10]$, 7, 8-DHF may have similar pharmacological effects. Therefore, in the present study, we investigated the 
repressive effect of 7, 8-DHF on pathologic neovascularization in vitro and explored its possible mechanisms, intending to identify a novel compound that would simultaneously inhibit angiogenesis and protect neurons.

\section{Methods}

\section{Cell Line and Culture}

The rhesus macaque choroid-retinal endothelial cell line (RF/6A) was achieved from Shanghai Zhong Qiao Xin Zhou Biotechnology Co., Ltd (Shanghai, China) and maintained in RPMI 1640 medium purchased from Hyclone (UT, USA) supplemented with 10\% fetal bovine serum obtained from Invitrogen (N.Y., USA ) at $37^{\circ} \mathrm{C}, 5 \% \mathrm{CO} 2$ and $95 \%$ humidified air.

\section{Media and Reagents}

Recombinant human VEGF165 was purchased from Novoprotein (Shanghai, China). Rabbit anti-human phosphor-VEGF receptor 2 and rabbit anti-human VEGF receptor 2 were obtained from Sigma-Aldrich (MO, USA). TRIZOL reagent was purchased from Invitrogen Life Technologies (Maryland, USA). Growth factorreduced Matrigel ${ }^{T M}$ Matrix was purchased from BD Biosciences Labware (Massachusetts, USA). All other reagents and solvents were obtained from Beyotime (Shanghai, China).

\section{Cell viability assay}

RF/6A cells in $100 \mu \mathrm{l}$ of medium were seeded with a density of 2000 per well in a 96-well plate and allowed to attach for 24 hours before the addition of drugs. Immediately after that, cells in a 96-well plate were pretreated with different concentrations (from 0 to $100 \mu \mathrm{M}$ ) of 7,8-DHF for 1 hour, then together with VEGF $(40 \mathrm{ng} / \mathrm{ml})$ or not for 24 hours. After that, the assay medium was aspirated from the well without disturbing the formazan crystals. The cell proliferation was detected with CCK-8 kit according to the manufacturer's instructions. The optical density was measured with a microplate reader at $450 \mathrm{~nm}$.

\section{Giemsa Staining}

RF/6A cells were seeded in 24-well plates at a density of $5 \times 10^{5}$ cells/well and stabilized for $24 \mathrm{~h}$. Then Cells were divided into 4 groups: the control group, 7,8-DHF group ( $25 \mu \mathrm{mol} / \mathrm{L} 7,8-\mathrm{DHF}$ treated for $24 \mathrm{~h})$, VEGF group (40 ng/ml VEGF treated for $24 \mathrm{~h}$ ), and 7,8-DHF plus VEGF treated groups (pretreated with $25 \mu \mathrm{mol} / \mathrm{L} 7,8-\mathrm{DHF}$ for $0.5 \mathrm{~h}$, then together with $40 \mathrm{ng} / \mathrm{ml} \mathrm{VEGF}$ for $24 \mathrm{~h}$ ). After incubation at $37^{\circ} \mathrm{C}$ for $24 \mathrm{~h}$, the wells were fixed with $4 \%$ paraformaldehyde, and the cells were stained with Giemsa solution (Jiancheng Bioengineering Institute, Nanjing, China) and examined under the phase-contrast microscope (Olympus BX40, Olympus) at $100 \times$ magnification.

\section{Cell migration assay}

Cell migration assay was performed in a 24-well plate with 8.0- $\mu \mathrm{m}$ pore-size transwell inserts (Corning, MA, USA). Cells were also divided into 4 groups: the control group, 7,8-DHF group, VEGF group, and 7,8- 
DHF plus VEGF treated groups. Firstly, the RF/6A cells were placed in the upper chamber $(5 x$ $10^{4} /$ chamber) in a final volume of $200 \mu \mathrm{l}$ of serum-free medium containing or not $25 \mu \mathrm{mol} / \mathrm{L} \mathrm{7,8-DHF}$. Then the bottom chamber was added with a final volume of $600 \mu \mathrm{l}$ of serum-free medium containing or not $40 \mathrm{ng} / \mathrm{ml}$ VEGF. After incubation at $37^{\circ} \mathrm{C}$ for $24 \mathrm{~h}$, the inserts were fixed with $4 \%$ paraformaldehyde, and the cells were stained with Giemsa solution. Cell numbers from 5 random visual fields were counted under a phase-contrast microscope (Olympus BX40, Olympus) at $100 \times$ magnification.

\section{Tube formation assay}

RF/6A cells in this assay were divided into 4 groups as previously described. Aliquots ( $250 \mu \mathrm{l})$ of Matrigel (Bedford, Massachusetts, USA) were added into a 24-well plate and incubated at $37^{\circ} \mathrm{C}$ for $60 \mathrm{~min}$. Trypsin-harvested cells $\left(30 \times 10^{4}\right.$ cells/well) suspended in $500 \mu \mathrm{l}$ of serum-free medium containing the indicated concentrations of 7,8-DHF and VEGF were seeded onto Matrigel. Enclosed capillary-like tube formation from three randomly chosen fields per well was photographed and counted after $6 \mathrm{~h}$ of incubation, and under an inverted phase-contrast microscope (Olympus BX40, Olympus) at $100 \times$ magnification.

\section{Flow Cytometry}

$\mathrm{RF} / 6 \mathrm{~A}$ cells in this assay were also divided into 4 groups. These cells were treated according to their respective grouping for another $24 \mathrm{~h}$ after being starved in the serum-free medium for $24 \mathrm{~h}$. Trypsinized and floating cells were collected and washed in PBS. Then these cells were treated according to the manufacturer 's instructions of Apoptosis Detection Kit (Abcam plc., Cambridge, MA). Finally, the treated suspensions of RF/6A cells were analyzed by flow cytometry. Cells stained with both PI and FITC were considered late apoptotic while singly stained with FITC were early apoptotic, and these two parts were counted as apoptotic cells.

\section{Hoechst33342 staining}

RF/6A cells were seeded in 24-well plates at a density of $5 \times 10^{5}$ cells/well and stabilized for $24 \mathrm{~h}$. Then cells in this assay were divided into 4 groups as previously described. After incubation at $37^{\circ} \mathrm{C}$ for $24 \mathrm{~h}$, cells were incubated with $10 \mathrm{~mol} / \mathrm{L}$ of Hoechst33342 for $10 \mathrm{~min}$ at room temperature and then washed with the medium for 3 times. Finally, cells were observed under a fluorescence microscope. The apoptotic cell rate was calculated by the following formula: apoptotic nucleus rate $=$ (apoptotic nucleus $/$ total nucleus) $\times 100 \%$.

\section{Western blot analysis}

$\mathrm{RF} / 6 \mathrm{~A}$ cells in the western blot analysis were seeded in plates and divided into 4 groups as before: the control group, 7,8-DHF treated group ( $25 \mu \mathrm{mol} / \mathrm{ml} \mathrm{7,8-DHF}$ treated for $24 \mathrm{~h})$, VEGF treated group (40 $\mathrm{ng} / \mathrm{ml}$ VEGF treated for $0.5 \mathrm{~h}$ ), and 7,8-DHF plus VEGF treated groups (pretreated with 7,8-DHF for $24 \mathrm{~h}$, then together with VEGF for $0.5 \mathrm{~h}$ ). The cells in $60 \mathrm{~mm}$ dishes treated according to their respective grouping were lysed in lysis buffer (Beyotime, China) supplemented with protease inhibitor. Protein concentrations of the lysate were measured with the BCA protein assay kit (Beyotime, China). Western 
blots were carried out according to the standard protocol and bands were analyzed by ImageJ software ( $\mathrm{NIH}$, Bethesda, MD, USA). The band intensities of p-VEGFR2 and VEGFR2 were quantified and normalized with VEGFR2 and GAPDH respectively.

\section{Statistics}

Statistical analysis was conducted with SPSS 19.0 software (IBM, Chicago, IL, USA). Data were expressed as the mean \pm SD. The significance of the differences between the groups was determined using the independent-samples t-test or one-way ANOVA analysis. A $p$ value $<0.05$ was considered statistically significant.

\section{Result}

\section{Effects of 7,8-DHF on RF/6A Proliferation}

The effects of 7,8-DHF on RF/6A proliferation were determined by CCK-8 assay. As showed in Fig. 1, VEGF $(40 \mathrm{ng} / \mathrm{ml})$ significantly elevated the levels of RF/6A proliferation as compared with the control (treated by $0 \mu \mathrm{M}$ 7,8-DHF $+0 \mathrm{ng} / \mathrm{ml}$ VEGF), and 7,8-DHF exhibited statistically significant inhibition on RF/6A cell proliferation regardless of in the presence of VEGF-A at the concentrations of 25, 50, and $100 \mu \mathrm{M}$. Thus, the concentration of $25 \mu \mathrm{M}$ was applied in the following experiments. Interestingly, in the presence of 25,50 , and $100 \mu \mathrm{M} 7,8-\mathrm{DHF}$, the proliferation of RF/6A cell between $0 \mathrm{ng} / \mathrm{ml} \mathrm{VEGF}$ and $40 \mathrm{ng} / \mathrm{ml}$ VEGF treated group was no statistical differences.

\section{Effects of 7,8-DHF on RF/6A on morphology}

The effects of 7,8-DHF on RF/6A morphology were examined by Giemsa staining. In the control group, RF/6A cells were displayed a cobblestone-like appearance and structural integrated (Fig. 2a). VEGF $(40 \mathrm{ng} / \mathrm{ml})$ could increase RF/6A cell density and reduce extracellular space (Fig. 2b). After administration of 7,8-DHF, whether or not in the presence of VEGF, RF/6A cell density decreased with a reduction in cytoplasm density, and extracellular space became increased. Furthermore, the appearance of the RF/6A cells became irregular with the naked nucleus, apoptosis body, and cell atrophy and debris (Fig. 2c-d).

\section{Effects of 7,8-DHF on RF/6A migration}

The migration study was assessed by the Transwell assay. As shown in Fig. 3, VEGF (40 ng/ml) significantly raised the numbers of cells transferred across the filter toward the lower surface $(135.40 \pm$ 10.95 vs. $97.00 \pm 15.37, p<0.05)$, and 7,8-DHF exhibited a strong inhibition on cell migration regardless of in the presence of VEGF-A at the concentration of $25 \mu \mathrm{M}$ (VEGF + 7,8-DHF-treated vs VEGF-treated: 69.60 \pm 11.01 vs. $135.40 \pm 10.95, p<0.05$; 7,8-DHF-treated vs control: $62.80 \pm 13.99$ vs. $97.00 \pm 15.37, p<0.05$ ). Interestingly, the migrated cells between 7,8-DHF and 7,8-DHF plus VEGF group were no statistical differences (69.60 \pm 11.01 vs. $62.80 \pm 13.99, p>0.05)$. 


\section{Effects of 7,8-DHF on RF/6A Capillary-Like Tube Formation}

The matrigel tube formation assay was performed to examine the actions of 7,8-DHF on the differentiation of RF/6A into vascular structures in vitro. As shown in Fig. 4, VEGF significantly promoted the formation of capillary-like structures as compared with the control group (965.33 \pm 167.48 vs. 530.67 \pm 83.01 ), and 7,8-DHF exhibited an inhibition on capillary-like tube formation regardless of in the presence of VEGF-A at the concentration of $25 \mu \mathrm{M}$ (VEGF + 7,8-DHF-treated vs VEGF-treated: $308.67 \pm 108.04 \mathrm{vs}$. $965.33 \pm 167.48, p<0.05 ; 7,8-D H F-t r e a t e d$ vs control: $288.00 \pm 77.32$ vs. $530.67 \pm 83.01, p<0.05)$. Interestingly, the numbers of tube nodes between 7,8-DHF and 7,8-DHF plus VEGF group were no statistical differences (308.67 \pm 108.04 vs. $288.00 \pm 77.32, p>0.05)$.

\section{Effects of 7,8-DHF on RF/6A apoptosis}

Considering that apoptosis might be correlated with the anti-angiogenic mechanism of 7,8-DHF, the apoptotic levels of RF/6A cells were examined by Flow Cytometry and Hoechst33342 staining. As shown in Fig. 5a, VEGF significantly prevented the apoptosis of RF/6A cells as compared with the control group ( $6.17 \pm 0.50$ vs. $10.49 \pm 1.26, p<0.05)$, and 7,8-DHF exhibited a promotion of both VEGF-induced $(6.17 \pm$ 0.50 vs $19.24 \pm 1.31, p<0.05)$ and no VEGF-induced $(10.49 \pm 1.26$ vs. $19.53 \pm 1.22, p<0.05)$ cell apoptosis at the concentration of $25 \mu \mathrm{M}$. Interestingly, the percentages of cell apoptosis between 7,8-DHF and 7,8DHF plus VEGF group were no statistical differences (19.53 \pm 1.22 vs.19.24 $\pm 1.31, p>0.05)$.

Similar to the results of flow cytometry, as shown in Fig. 5c, Hoechst33342 staining also revealed that VEGF significantly reduced the rate of nuclei apoptosis as compared with the control group $(2.42 \pm 1.08$ vs. $7.90 \pm 1.02, p<0.05)$, and 7,8-DHF $(25 \mu \mathrm{M})$ significantly raised the percentages of apoptotic nuclei in RF/6A cells regardless of in the presence of VEGF-A (VEGF + 7,8-DHF-treated vs VEGF-treated: $16.02 \pm$ 2.51 vs $2.42 \pm 1.08, p<0.05$; 7,8-DHFtreated vs control: $16.28 \pm 1.66$ vs. $7.90 \pm 1.02, p<0.05$ ). Interestingly, the cell apoptosis percentages between 7,8-DHF and 7,8-DHF plus VEGF group were also no statistical differences $(16.28 \pm 1.66$ vs. $16.02 \pm 2.51, p>0.05)$.

\section{Effects of 7,8-DHF on VEGF Receptor 2 Signaling Pathway}

To determine whether 7,8-DHF had any effect on the VEGFR2's activity, the changes of VEGFR2's Tyr phosphorylation were assessed in RF/6A cells. As shown in Fig. 6(a-b), VEGF significantly increased the phosphorylation of VEGFR2 as compared with the control group (1.19 \pm 0.02 vs. $1.00 \pm 0.05, p<0.05)$, and 7,8-DHF $(25 \mu \mathrm{M})$ exhibited an apparent inhibition on VEGFR2 phosphorylation regardless of in the presence of VEGF-A (VEGF + 7,8-DHF-treated vs VEGF-treated: $0.82 \pm 0.01$ vs $1.19 \pm 0.02, p<0.05 ; 7,8$-DHFtreated vs control: $0.80 \pm 0.01$ vs. $1.00 \pm 0.05, p<0.05)$. Interestingly, the phosphorylated VEGFR2 proteins between 7,8-DHF and 7,8-DHF plus VEGF group were no statistical differences ( $0.82 \pm 0.01$ vs. $0.80 \pm 0.01$, $p>0.05)$. Furthermore, the total VEGFR2 proteins among the four groups were also not significantly different $(F=1.192, p>0.05)$.

\section{Discussion}


Choroidal and retinal angiogenesis are the primary causes of vision loss in patients with neovascular $A M D$, proliferative $D R$, retinopathy of prematurity, and other diseases. It should be noted that these retinal vascular disorders are always accompanied by neuronal damage[11]. Although anti-VEGF treatments have been extensively administered for neovascular eye diseases[12], they are likely to aggravate this neuronal injury and thus deteriorate visual function[13]. To solve this dilemma, a treatment that can protect neurons and simultaneously inhibit angiogenesis is urgently needed. 7,8-DHF, a naturallyoccurring flavone, has been reported to possess multiple beneficial effects, such as neuroprotective effect, anti-inflammatory, and vasorelaxing[14]. Recently, growing evidence suggests that 7, 8-DHF may also inhibit pathological neovascularization[7], although this has not yet been confirmed. In the present study, we observed that $25 \mu \mathrm{M}$ 7,8-DHF significantly prevented the proliferation, migration, and tube formation of RF/6A cells and promoted their apoptosis in vitro regardless of in the presence of VEGF, indicating that 7,8-DHF has inhibitory effects on angiogenesis in vitro. This result, together with the previous findings that low concentration $(500 \mathrm{nM})$ of 7,8-DHF provides neuroprotection via the activation of TrkB receptor while high concentration $(25 \mu \mathrm{M})$ of that via its potent antioxidant activity[15-17], make 7,8-DHF a potential candidate for the treatment of retinal vascular disease co-existing with neuropathy.

Many studies have revealed that 7,8-DHF at the concentration of $25 \mu \mathrm{M}$ is nontoxic and even protective to several types of cells in vitro[16-18], whereas in the present experiment we discovered that $25 \mu \mathrm{M} 7,8$ DHF significantly inhibits the viability of RF/6A cells. The varying effects of 7, 8-DHF in these cell types may be attributed to its different pharmacological actions. VEGF is a potent proangiogenic factor that stimulates the proliferation, migration, and tube formation of endothelial cells and inhibits their apoptosis[19]. These biological VEGF signaling pathways are mainly mediated by VEGFR-2 receptor, which is abundant on the surface of vascular endothelial cells[20]. Phosphorylation of VEGFR-2 induces multiple downstream signals that subsequently promote angiogenesis in endothelial cells[21]. Thus, VEGF/VEGFR2 signal pathway is an important target for studying the angiogenesis inhibiting effects of 7, 8-DHF. In the present study, we demonstrated that although VEGFR2 expression was relatively constant, phosphorylated VEGFR2 levels were significantly decreased in RF/6A cells pretreated with 7, 8-DHF for 2 hours, in both the presence and absence of VEGF, indicating that 7, 8-DHF modulates the VEGFR2 signaling pathway by deactivating VEGFR2 rather than down-regulating its expression. There are two possible explanations for the observed 7, 8-DHF-induced signal deactivation. One is that 7, 8-DHF may down-regulate the expression of VEGF-A in RF/6A cells and thus inhibit signal transmission. According to this hypothesis, the extent of angiogenesis and level of phosphorylated VEGFR2 protein should be significantly different between the 7, 8-DHF-treated and 7, 8-DHF plus VEGF-treated groups, which contradicts our findings in this study. The other explanation is that 7, 8-DHF prevents VEGFR2 activation by interfering with the binding of VEGF to VEGFR2. This well explains why even if VEGF levels are elevated in RF/6A cells, the levels of angiogenesis and phosphorylated VEGFR2 protein remain unchanged in the presence of 7,8-DHF $(25 \mu \mathrm{M})$. This assumption is also supported by a previous study using a combination of molecular docking, computational mapping tools, and molecular dynamics, which showed that 7, 8-DHF may exert its effects on VEGFR2 via the intracellular kinase domain[7]. Collectively, the above evidence suggests that 7, 8-DHF inhibits angiogenesis in RF/6A cells in vitro by 
suppressing the phosphorylation of VEGFR2, although the exact mechanism of VEGFR2 dephosphorylation induced by 7, 8-DHF remains to be elucidated.

In this study, we comprehensively investigated the antiangiogenic effects of 7, 8-DHF on RF/6A cells, which were mainly used in the study of chorioretinal neovascular diseases. However, whether this medicine has similar inhibitory effects on other types of vascular endothelial cells, such as human umbilical vein endothelial cells (HUVEC), remains to be studied. Furthermore, in vivo studies are needed to obtain a comprehensive understanding of the observed effect and the mechanism underlying the effects of this compound on choroidal and retinal angiogenesis.

\section{Conclusions}

In summary, the present study revealed the inhibitory effect of 7, 8-DHF on angiogenic properties in vitro. This finding, combining with the previous discoveries that low concentration (500 nM) of 7,8-DHF provides neuroprotection via the activation of TrkB receptor while high concentration $(25 \mu \mathrm{M})$ of that via its potent antioxidant activity[15-17], suggests the great potential of 7,8-DHF for the treatment of ocular diseases with coexisting angiogenesis and neuropathy, such DR, AMD, neovascular glaucoma, etc. Since there are numerous patients with these diseases, medicine with the above pharmacological activities could provide great benefits.

\section{Abbreviations}

\section{7,8-DHF}

7,8-dihydroxyflavone; PDR:proliferative diabetic retinopathy; AMD:age-related macular degeneration; TrkB:tropomyosin-associated kinase receptor B; RF/6A:rhesus macaque choroid-retinal endothelial cell line; HUVEC:human umbilical vein endothelial cells

\section{Declarations}

\section{Ethics approval and consent to participate}

Not applicable

\section{Consent for publication}

Not applicable

\section{Availability of data and materials}

The datasets generated and analysed during the current study are available from the corresponding author on reasonable request. 
The authors do not have any conflict of interest to report and have no proprietary interest in any of the materials mentioned in this article

\section{Funding}

This research was supported by the National Natural Science Foundation of China (NO.81570842). The funding body had no influence on the design, collection, analysis or interpretation of the data, or in writing the manuscript.

\section{Authors' contributions}

XFM suggested concept of study, XWC performed to conduct study and wrote the manuscript. Collection, analysis and interpretation of data were performed by XWC, WY, SQY, SQW, GL, XFM. All authors read and approved the final manuscript.

\section{Acknowledgements}

Not applicable

\section{References}

1. Li Y, Zhou Y. Interleukin-17: The Role for Pathological Angiogenesis in Ocular Neovascular Diseases. Tohoku J Exp Med. 2019;247(2):87-98. doi:10.1620/tjem.247.87.

2. Rivera JC, Holm M, Austeng D, Morken TS, Zhou TE, Beaudry-Richard A, et al. Retinopathy of prematurity: inflammation, choroidal degeneration, and novel promising therapeutic strategies. J Neuroinflammation. 2017;14(1):165. doi:10.1186/s12974-017-0943-1.

3. Zhao Y, Singh RP. The role of anti-vascular endothelial growth factor (anti-VEGF) in the management of proliferative diabetic retinopathy. Drugs Context. 2018;7:212532. doi:10.7573/dic.212532.

4. Hollander MR, Horrevoets AJ, van Royen N. Cellular and pharmacological targets to induce coronary arteriogenesis. Curr Cardiol Rev. 2014;10(1):29-37. doi:10.2174/1573403x113099990003.

5. Gerhardinger C, Brown LF, Roy S, Mizutani M, Zucker CL, Lorenzi M. Expression of vascular endothelial growth factor in the human retina and in nonproliferative diabetic retinopathy. $\mathrm{Am} \mathrm{J}$ Pathol. 1998;152(6):1453-62.

6. Amin M, Desai M, Trinkaus K, Brown A, Wang-Gillam A, Tan B, et al. Phase Il trial of levocetirizine with capecitabine and bevacizumab to overcome the resistance of antiangiogenic therapies in refractory metastatic colorectal cancer. J Gastrointest Oncol. 2019;10(3):412-20. doi:10.21037/jgo.2019.02.01.

7. Chitranshi N, Gupta V, Kumar S, Graham SL. Exploring the Molecular Interactions of 7,8Dihydroxyflavone and Its Derivatives with TrkB and VEGFR2 Proteins. Int J Mol Sci. 2015;16(9):21087-108. doi:10.3390/ijms160921087.

8. Ren E, Roncacé V, Trazzi S, Fuchs C, Medici G, Gennaccaro L, et al. Functional and Structural Impairments in the Perirhinal Cortex of a Mouse Model of CDKL5 Deficiency Disorder Are Rescued by 
a TrkB Agonist. Front Cell Neurosci. 2019;13:169. doi:10.3389/fncel.2019.00169.

9. He L, Wu Y, Lin L, Wang J, Wu Y, Chen Y, et al. Hispidulin, a small flavonoid molecule, suppresses the angiogenesis and growth of human pancreatic cancer by targeting vascular endothelial growth factor receptor 2-mediated PI3K/Akt/mTOR signaling pathway. Cancer Sci. 2011;102(1):219-25. doi:10.1111/j.1349-7006.2010.01778.x.

10. Wang Z, Wang N, Han S, Wang D, Mo S, Yu L, et al. Dietary compound isoliquiritigenin inhibits breast cancer neoangiogenesis via VEGF/VEGFR-2 signaling pathway. PLoS One. 2013;8(7):e68566. doi:10.1371/journal.pone.0068566.

11. McAllister IL, Vijayasekaran S, Zhang D, McLenachan S, Chen FK, Yu DY. Neuronal degeneration and associated alterations in cytokine and protein in an experimental branch retinal venous occlusion model. Exp Eye Res. 2018;174:133-46. doi:10.1016/j.exer.2018.05.025.

12. Pham B, Thomas SM, Lillie E, Lee T, Hamid J, Richter T, et al. Anti-vascular endothelial growth factor treatment for retinal conditions: a systematic review and meta-analysis. BMJ Open. 2019;9(5):e022031. doi:10.1136/bmjopen-2018-022031.

13. Rappoport D, Morzaev D, Weiss S, Vieyra M, Nicholson JD, Leiba H, et al. Effect of intravitreal injection of bevacizumab on optic nerve head leakage and retinal ganglion cell survival in a mouse model of optic nerve crush. Invest Ophthalmol Vis Sci. 2013;54(13):8160-71. doi:10.1167/iovs.1312771.

14. Choi JW, Lee CW, Lee J, Choi DJ, Sohng JK, Park YI. 7,8-Dihydroxyflavone inhibits adipocyte differentiation via antioxidant activity and induces apoptosis in 3T3-L1 preadipocyte cells. Life Sci. 2016;144:103-12. doi:10.1016/j.Ifs.2015.11.028.

15. Gupta VK, You Y, Li JC, Klistorner A, Graham SL. Protective effects of 7,8-dihydroxyflavone on retinal ganglion and RGC-5 cells against excitotoxic and oxidative stress. J Mol Neurosci. 2013;49(1):96104. doi:10.1007/s12031-012-9899-x.

16. Chen J, Chua KW, Chua CC, Yu H, Pei A, Chua BH, et al. Antioxidant activity of 7,8-dihydroxyflavone provides neuroprotection against glutamate-induced toxicity. Neurosci Lett. 2011;499(3):181-5. doi:10.1016/j.neulet.2011.05.054.

17. Han X, Zhu S, Wang B, Chen L, Li R, Yao W, et al. Antioxidant action of 7,8-dihydroxyflavone protects PC12 cells against 6-hydroxydopamine-induced cytotoxicity. Neurochem Int. 2014;64:18-23. doi:10.1016/j.neuint.2013.10.018.

18. Ryu MJ, Kang KA, Piao MJ, Kim KC, Zheng J, Yao CW, et al. 7,8-Dihydroxyflavone protects human keratinocytes against oxidative stress-induced cell damage via the ERK and PI3K/Akt-mediated Nrf2/HO-1 signaling pathways. Int J Mol Med. 2014;33(4):964-70. doi:10.3892/ijmm.2014.1643.

19. Yesildal F, Koc E, Tas A, Ozgurtas T. Angiopoietins in Human Breast Milk. Breastfeed Med. 2016;11:366-9. doi:10.1089/bfm.2016.0065.

20. Huang M, Huang B, Li G, Zeng S. Apatinib affect VEGF-mediated cell proliferation, migration, invasion via blocking VEGFR2/RAF/MEK/ERK and PI3K/AKT pathways in cholangiocarcinoma cell. BMC Gastroenterol. 2018;18(1):169. doi:10.1186/s12876-018-0870-3. 
21. Yan XC, Cao J, Liang L, Wang L, Gao F, Yang ZY, et al. miR-342-5p Is a Notch Downstream Molecule and Regulates Multiple Angiogenic Pathways Including Notch, Vascular Endothelial Growth Factor and Transforming Growth Factor $\beta$ Signaling. J Am Heart Assoc. 2016;5(2)doi:10.1161/JAHA.115.003042.

\section{Figures}

\section{non-VEGF treated \\ $\square$ 40ng/ml VEGF treated}

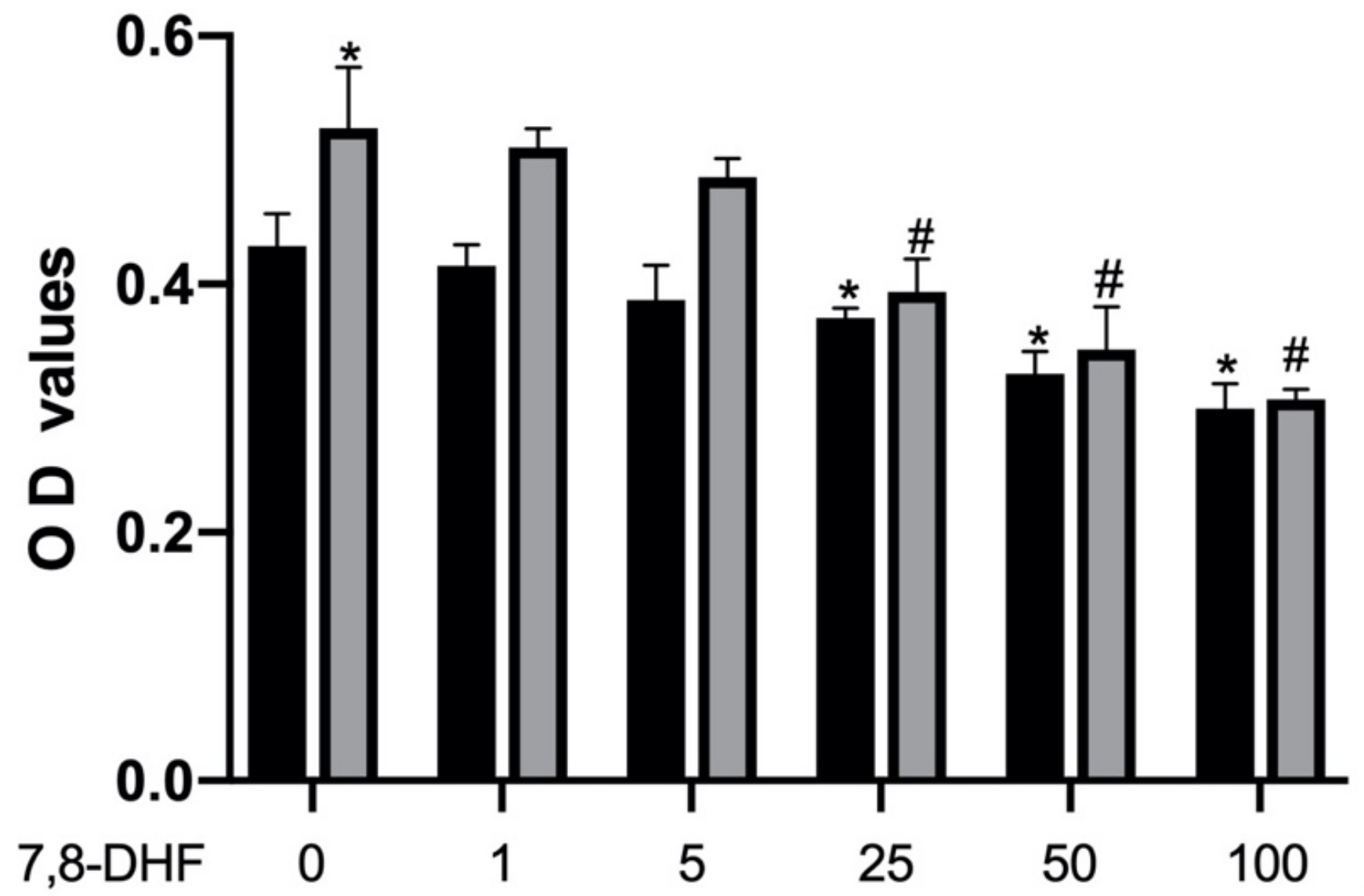

(uM)

Figure 1

Effects of 7,8-DHF on proliferation of RF/6A cells. 7,8-DHF weakened both VEGF-induced and no VEGFinduced proliferation of RF/6A cells in a dose-dependent manner. ${ }^{*} p<0.05$ vs. $0 \mu \mathrm{M} 7,8-\mathrm{DHF}+0 \mathrm{ng} / \mathrm{ml}$ VEGF-A group; $\# \mathrm{p}<0.05$ vs. $0 \mu \mathrm{M}$ 7,8-DHF+ 40ng/ml VEGF-A group. 

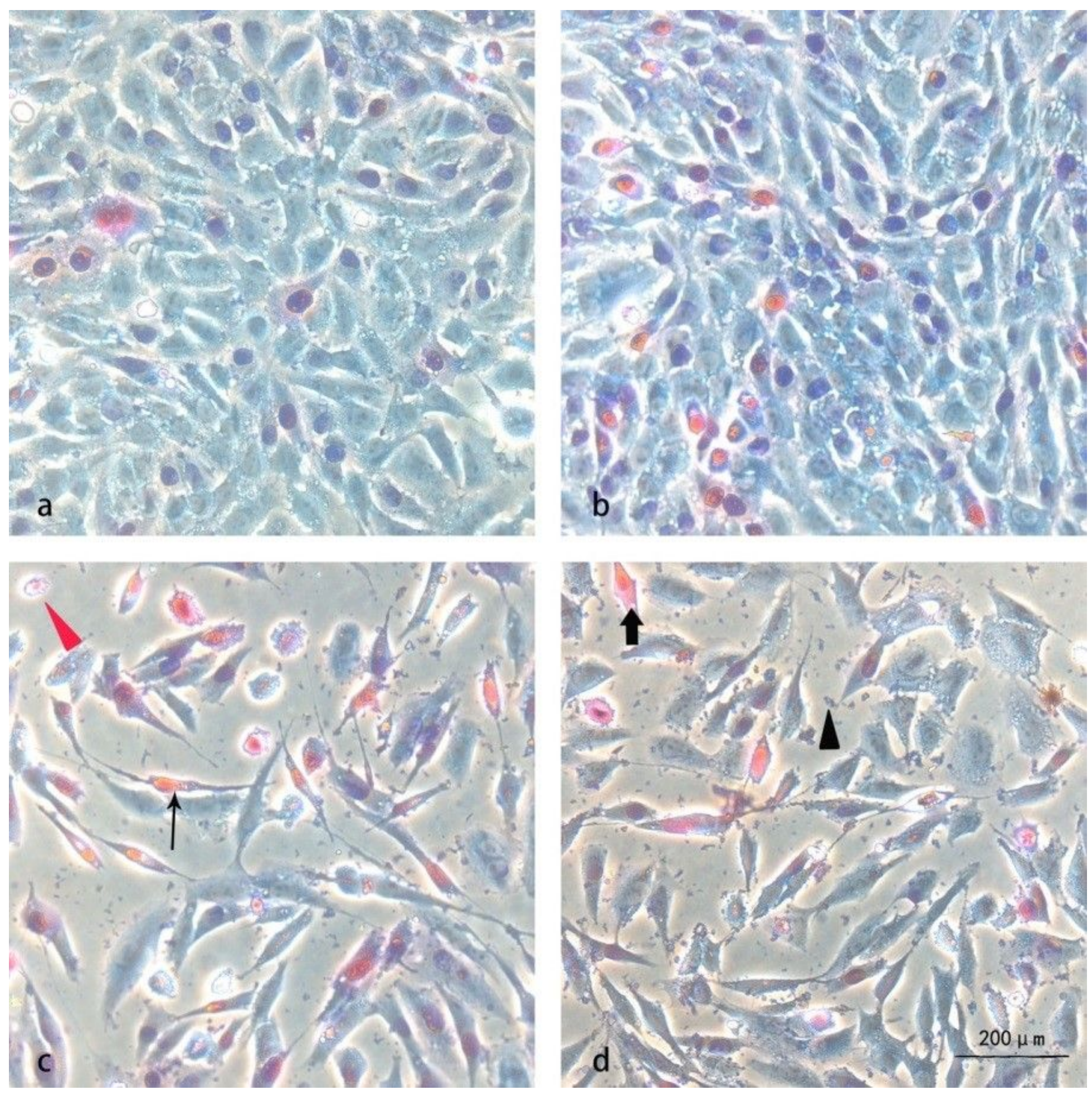

\section{Figure 2}

Effects of 7,8-DHF on RF/6A cell morphology $(\times 200)$. Representative figures of Giemsa staining were shown: control group (a); VEGF treated group (b); 7,8-DHF treated group (c); 7,8-DHF plus VEGF treated group (d). The long arrow, short arrow, black triangle, and red triangle indicated cell atrophy, naked nucleus, cell debris, and apoptosis body respectively. Bar scale: $200 \mu \mathrm{m}$. 

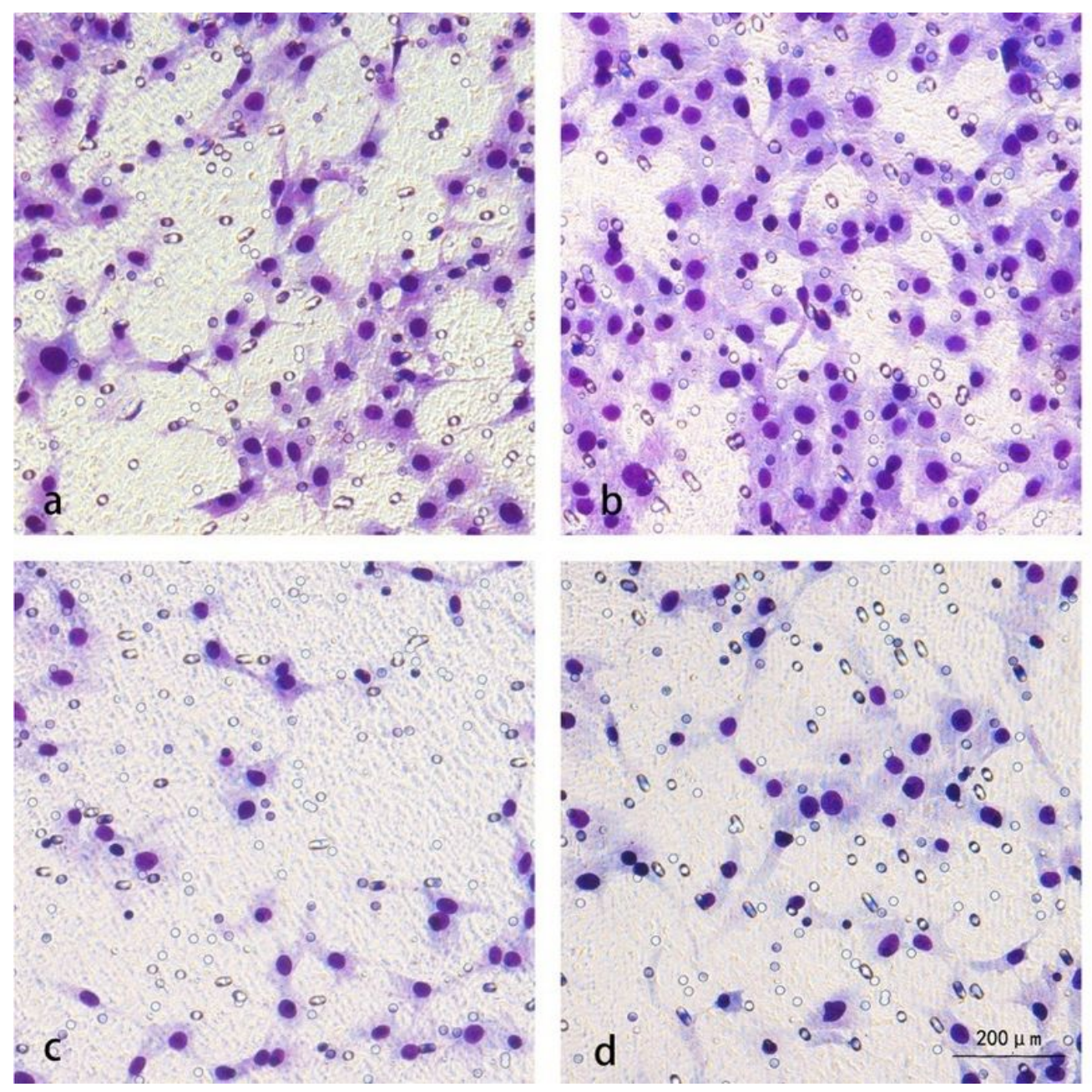

e

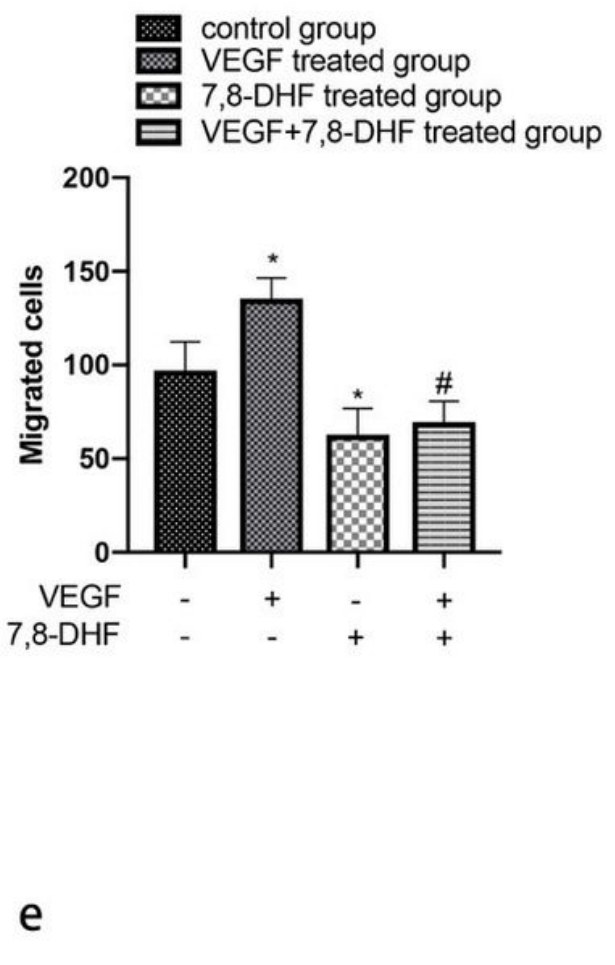

Figure 3

Effects of 7,8-DHF on RF/6A migration ( $(200)$. The migratory activity of RF/6A cells after their respective treatments was estimated based on the number of cells migrated through the filter inserts. Representative figures of RF/6A migratory activity were shown: control group (a); VEGF treated group (b); C: 7,8-DHF treated group (c); 7,8-DHF plus VEGF treated group (d). Quantitative analysis of the number of migrated cells expressed as means $\pm S D(e) .{ }^{*} p<0.05$ vs. control group, $\# p<0.05$ vs. VEGF treated group. Bar scale: $200 \mu \mathrm{m}$. 

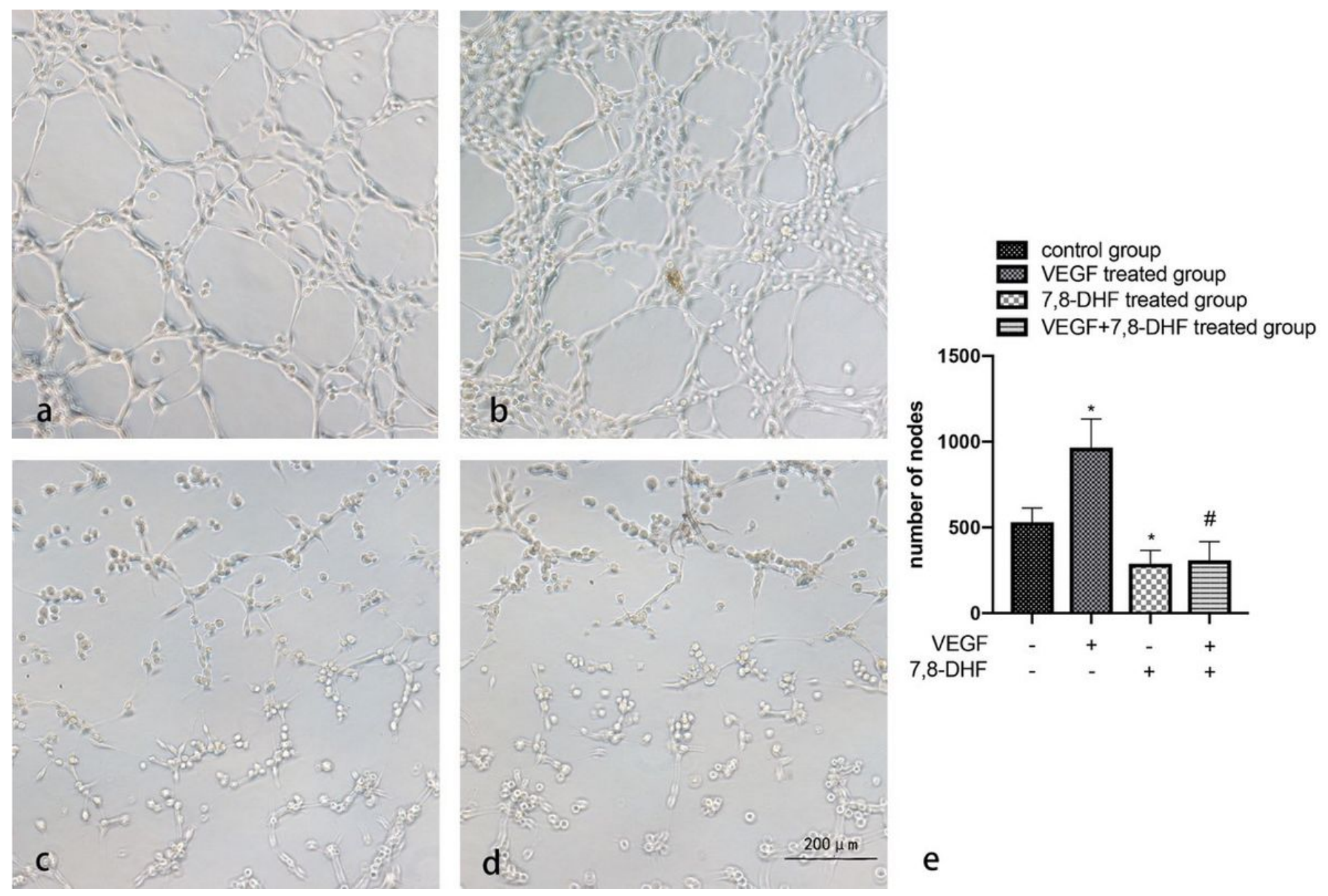

Figure 4

Effects of 7,8-DHF on RF/6A tube formation. Representative figures of tube-like structures were shown: control group (a); VEGF treated group (b); 7,8-DHF treated group (c); 7,8-DHF plus VEGF treated group (d). Quantitative analysis of the number of nodes expressed as means \pm SD (e). \# $p<0.05$ vs. VEGF treated group, ${ }^{*} p<0.05$ vs. control group. Bar scale: $200 \mu \mathrm{m}$. 

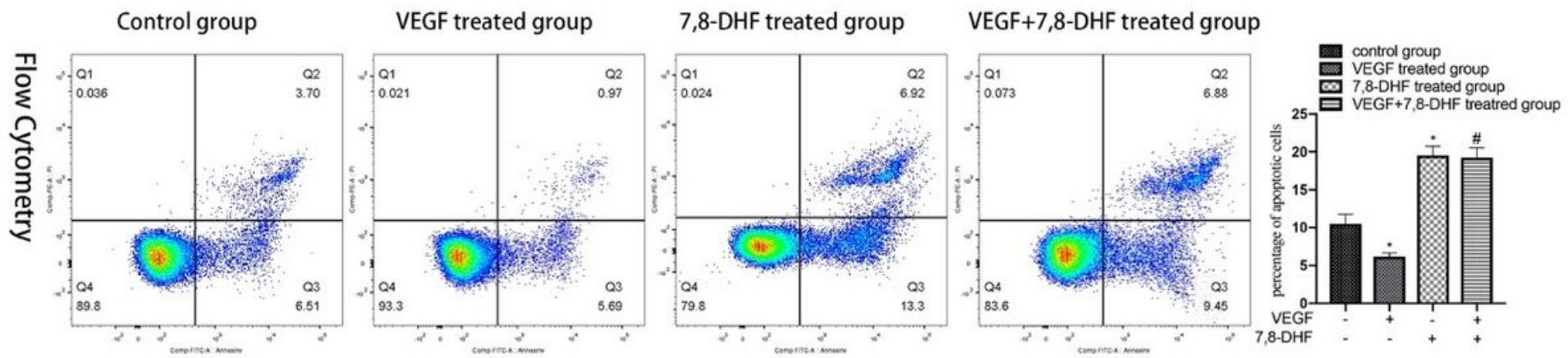

a
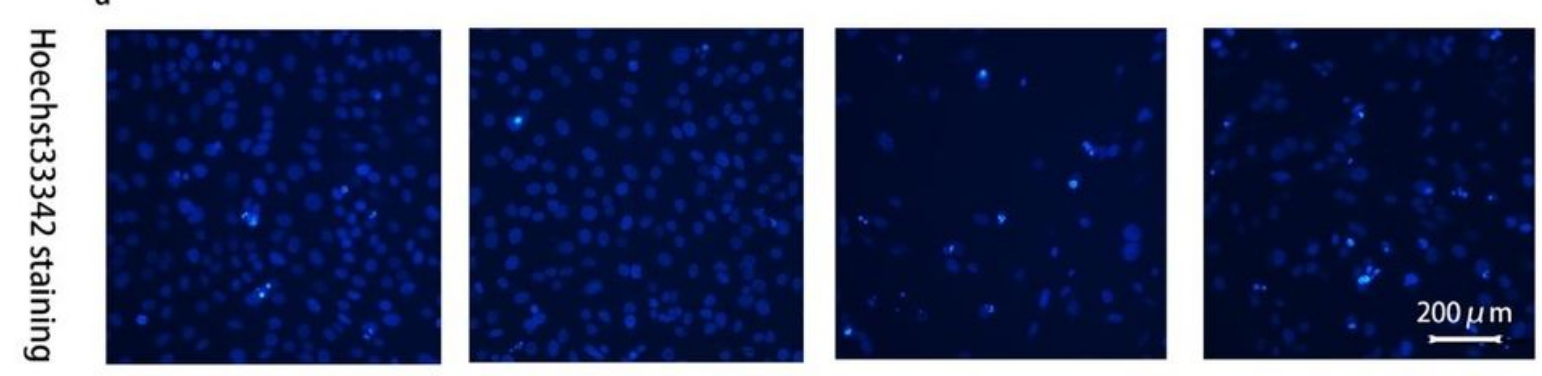

b

c

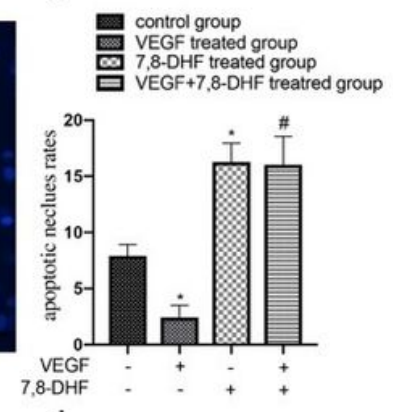

d

\section{Figure 5}

Effects of 7,8-DHF on RF/6A apoptosis. (a): Representative figures of flow cytometry on RF/6A cells treated according to their respective grouping; (b): Quantification of apoptosis detected by flow cytometry; (c): Representative figures of Hoechst33342 staining in RF/6A cells ( $(100)$; (d): Quantification of apoptotic nucleus stained by Hoechst33342. * $p<0.05$ vs. control group, $\# p<0.05$ vs. VEGF treated group. Bar scale: $200 \mu \mathrm{m}$.

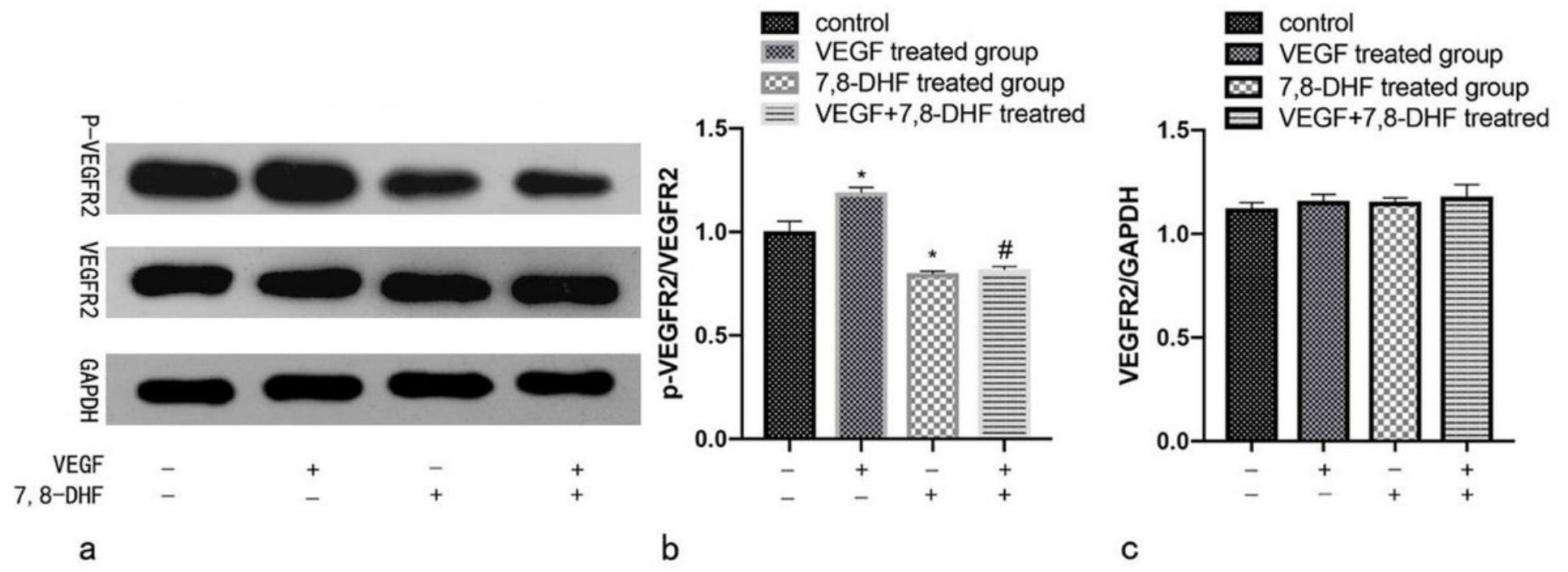

Figure 6 
Effects of 7,8-DHF on the VEGF receptor 2 signaling pathway. A: Representative blots of $p$-VEGFR2, VEGFR2, and GAPDH. The band intensities of p-VEGFR2 and VEGFR2 were quantified and normalized with VEGFR2 and GAPDH respectively; B: Levels of p-VEGFR2 protein expressed as the mean \pm SD of at least 3 independent experiments; C: Levels of VEGFR2 protein expressed as the mean \pm SD of at least 3 independent experiments. ${ }^{*} p<0.05$ vs. control group, $\# p<0.05$ vs. VEGF treated group.

\section{Supplementary Files}

This is a list of supplementary files associated with this preprint. Click to download.

- originalblotiamge.pdf 